University of Nebraska - Lincoln

DigitalCommons@University of Nebraska - Lincoln

Sociology Department, Faculty Publications

Sociology, Department of

$12-2012$

\title{
Individual and social network sexual behavior norms of homeless youth at high risk for HIV infection
}

Kimberly A. Tyler

University of Nebraska-Lincoln, kim@ktresearch.net

Lisa A. Melander

Kansas State University, Imeland@ksu.edu

Follow this and additional works at: https://digitalcommons.unl.edu/sociologyfacpub

Part of the Sociology Commons

Tyler, Kimberly A. and Melander, Lisa A., "Individual and social network sexual behavior norms of homeless youth at high risk for HIV infection" (2012). Sociology Department, Faculty Publications. 210. https://digitalcommons.unl.edu/sociologyfacpub/210

This Article is brought to you for free and open access by the Sociology, Department of at DigitalCommons@University of Nebraska - Lincoln. It has been accepted for inclusion in Sociology Department, Faculty Publications by an authorized administrator of DigitalCommons@University of Nebraska - Lincoln. 


\title{
Individual and social network sexual behavior norms of homeless youth at high risk for HIV infection
}

\author{
Kimberly A. Tyler \\ Department of Sociology, University of Nebraska-Lincoln \\ Corresponding author - 717 Oldfather Hall, Lincoln, NE 68588-0324; kim@ktresearch.net \\ Lisa A. Melander \\ Department of Sociology, Anthropology, and Social Work, Kansas State University
}

\begin{abstract}
Although previous research shows that homeless youth engage in numerous risky sexual behaviors, little is known about whether or not specific rules govern this conduct within their social networks and how group norms influence subsequent sexual actions. The current study utilizes 19 in-depth interviews with homeless youth to investigate different elements of their sexual behavior. Findings reveal that their decision to have sex generally depends on chemistry and physical appearance whereas a potential partner's risky sexual history and heavy substance use discourages youth from engaging in sex. Both males and females discuss condom usage as it relates to unknown sexual history, availability, pregnancy, and the prevention of sexually transmitted infections (STIs). Sixteen homeless youth indicate that they do not discuss safe sex practices with their partners or social network members.
\end{abstract}

Keywords: homeless youth, sexual norms, social networks, risky sexual behaviors

\section{Introduction}

Young people ages 13 to 24 are at high risk for HIV (human immunodeficiency virus) infection, and within this age group, racial/ethnic minorities, females, and gay and bisexual youth are at particularly high risk (Centers for Disease Control and Prevention, 2008). Because many homeless youth participate in drug and sexual risk behaviors, often with their social network members and other street individuals, they are also at significantly greater risk for STIs and HIV (Kipke et al., 1998; Rice et al., 2007; Tyler, 2008) compared to general populations.

Although quantitative studies have documented that homeless youth engage in risky sexual behaviors such as unprotected sex, having multiple sexual partners, and trading sex (Bailey et al., 1998; Halcon and Lifson, 2004; Rew et al., 2008; Tevendale et al., 2009), these studies do not examine the norms that exist within their social networks regarding safe sex practices. Studying peer group norms are critical because if social networks as a whole are aware of the risks associated with inconsistent condom use, the group members may practice safe sex behavior. In contrast, those who belong to social networks where the norms regarding safe sexual practices are absent may be at greater risk. We use a qualitative approach to explore perceived norms of sexual activity within homeless youths' peer groups in order to understand their views regarding safe sex practices. It is also our hope that this information will be useful to service providers and work toward changing homeless youths' social network norms regarding safe sex through community, media, and street outreach initiatives thereby potentially reducing their risk for HIV infection.

\section{Literature review}

\subsection{Child sexual abuse and street survival strategies}

There are several correlates of unsafe sexual behavior that are related to the lifestyles and experiences of homeless youth that are widely encountered by this population. For example, child sexual abuse among homeless youth has been linked to unsafe sexual practices (Johnson et al., 1996; Rotheram-Borus et al.; 1996; Tyler et al., 2000) including low rates of condom usage and multiple sex partners (Bailey et al., 1998; Halcon and Lifson, 2004; Johnson et al., 1996; MacKellar et al., 2000; Rew et al., 2008; Tyler et al., 2001), both of which place youth at higher risk for STIs and HIV (Kipke et al., 1998; Rice et al., 2007; Tyler, 2008). Additionally, sexual survival strategies among some homeless youth include trading sex for food, shelter, money, or drugs (Tyler and Johnson, 2004; Van Leeuwen et al., 2004) and this behavior, along with high rates of substance use also places young people at greater risk for contracting STIs and HIV (American Public Human Services Association, 1999; Farrow et al., 1992). Though this quantitative research has demonstrated an association between sexual abuse and trading sex with risky sexual behaviors, these studies do not reveal why some homeless youth practice safe sex whereas others do not. 


\subsection{Social networks}

Social networks, which are generally composed of people with whom an individual regularly associates and spends the majority of their time (Tyler, 2008), have been found to influence the behaviors of homeless youth. Young people enter these groups by choice, chance, coercion, or for protection (Cairns et al., 1995; Hagan and McCarthy, 1997), and the attitudes and norms of the group may be beneficial or detrimental to the homeless young person. If network norms are consistent with risky sexual behavior, then members of the group may be less likely to endorse safe sex practices such as condom usage during sex. For example, Rice, Stein, and Milburn (2008) found that homeless youth who had more network members engaging in HIV risk behaviors personally had increased sexual risk taking activities.

\subsection{Theoretical framework}

According to social norms theory (Perkins, 2002), people generally do not accurately report the frequency with which their peers engage in risky behaviors such as unsafe sex and that these misperceptions have an effect on the person's own behavior. That is, if the youth thinks the behavior occurs more frequently than it really does, the result is that $\mathrm{s} /$ he is more likely to engage in this behavior (Martens et al., 2006). Thus, if homeless youth believe that their social network members rarely use condoms when having sex, then homeless youth themselves are likely to engage in unsafe sex.

\subsection{Current study}

Despite the inherent risks, individuals often adhere to the attitudes and behaviors of their social networks to avoid sanctions for nonconformity (Fisher, 1988), and homeless youth whose social networks are not supportive of preventative HIV risk behavior may participate in a greater number of unsafe sexual practices. Research finds that social networks that include other homeless youth are more likely to engender risk because of the high rate of substance use and risky sexual behaviors found among these individuals (Hagan and McCarthy, 1997; Tyler and Johnson, 2004; Tyler et al., 2007; Whitbeck and Hoyt, 1999). Moreover, homeless youth who participate in these activities generally have friends who engage in similar practices (Kipke et al., 1998). Thus, to fill an important gap in the literature and to better understand the social environment and individual decision making process of homeless youth as it relates to sexual practices and related behaviors within their social networks, we considered the following research questions: 1) What attitudes or norms influence homeless youths' decisions to have sex? 2) What are the norms surrounding condom use? 3) What are the ways in which homeless youth discuss safe sex practices within their peer group?

\section{Design and methods}

\subsection{Sample}

The qualitative data for the present study are from the Social Network and Homeless Youth Project, a larger study designed to examine the effect of social network characteristics on homeless youths' HIV risk behaviors. A total of 249 homeless youth (137 females; 112 males) participated in quantitative interviews in shelters and on the streets from January 2008 to March 2009 in three Midwestern cities in the United States. The same three interviewers conducted both the quantitative and qualitative interviews.

\subsection{Data collection}

We selected three female interviewers, with prior quantitative and qualitative interview experience with homeless youth, to conduct the interviews because of their extensive work with homeless youth in shelter, street outreach, and research settings. Additionally, because two interviewers had previously worked at two of the sampled shelters and one interviewer was currently employed with a third agency, they were known and trusted by many of the participants. Furthermore, the interviewers routinely attended "group sessions" in the evenings with homeless youth, which further enhanced their rapport with the young people. All interviewers completed the Collaborative Institutional Review Board (IRB) Training Initiative course for the protection of human subjects in research. Selection criteria for the larger study required participants to be between the ages of 14 and 21 and meet our definition of runaway or homeless. Runaway refers to youth under age 18 who have spent the previous night away from home without the permission of parents or guardians. Homeless youth are those who have spent the previous night with a stranger, in a shelter or public place, on the street, in a hotel room, staying with friends (e.g., couch surfing), or other places not intended as their resident domicile (Ennett, Bailey, \& Federman, 1999).

Participants for the qualitative interviews were selected from the original sample of 249 to represent different gender, racial/ethnic, and sexual orientation groups using a purposive sampling strategy (Miles \& Huberman, 1994). After the completion of the quantitative survey instrument, interviewers selected youth from these different demographic groups to participate in an in-depth interview that was conducted approximately one week later. Interviewers were instructed to oversample racial/ethnic and sexual minorities because they are at greater risk for acquiring HIV ( Centers for Disease Control and Prevention, 2002a, 2002b), which was the focus of the larger research project. All selected youth participated in these qualitative interviews. Interviewers gave the youth a card with their name and phone number along with the day and time for the in-depth interview. Youth were allowed to use shelter agency telephones to contact interviewers if they needed to reschedule the appointment. They were paid $\$ 30$ for completing the qualitative interview which lasted approximately 1 to $11 / 2 \mathrm{~h}$. All in-depth interviews took place in a private room at the shelters. Informed consent was obtained from all youth prior to the interview. Interviewers offered agency services or referrals to all youth (e.g., shelter, food services, and counseling). Participants were asked a series of open-ended questions, and all interviews were audiotaped and transcribed verbatim. Pseudonyms are used to preserve confidentiality. The university IRB approved this study.

\subsection{Interviewer guide}

The guide for the qualitative interviews consisted of open-ended questions and probes that expounded upon topics in the quantitative survey where youth could list up to five people that they see or spend most of their time with as well as three people they had sexual relations with in the past six months for a total of eight social network members. The sexual partners could be people on their original network list of five or new ones not previously mentioned. In either scenario, sexual partners listed are considered part of the youth's social network. This approach has been used in past research on social networks and high-risk populations of similar age (Montgomery et al., 2002). The qualitative interviews began with the following statement: "Today I would like to talk with you in-depth about the same people that you told me about last time we did your other interview." As a reminder, youth were then given a card with the initials of the people that they discussed in the survey.

\subsection{Data analysis}

All data analyses were performed by the authors. The interview transcriptions were imported into ATLAS.ti, a data management software program (Muhr, 2004) by the second author. The first step in the preliminary data analysis involved rereading each interview transcript in 
its entirety in order to gain a deeper sense of the data as a whole. Because we were interested in perceived norms of sexual activity within homeless youth's social networks, we then focused on the transcription sections that related to interview questions on this topic. Each author conducted open coding independently and then reconvened for discussion.

We assessed validity by triangulating the data by building evidence for a code or theme (e.g., norms regarding safe sex practices) from several individuals (Creswell \& Plano Clark, 2011). For intercoder agreement, we used a predetermined coding scheme and a qualitative codebook to identify whether we assigned the same or different codes between text passages (Miles \& Huberman, 1994). In cases in which the intercoder agreement between the authors was low or discrepancies existed, we obtained consensus through deliberation and re-evaluating our coding and themes. Finally, we conducted a collaborative data conference with other colleagues who have experience with qualitative data analysis in order to assess the validity of our findings. Table 1 presents sample quotes for each qualitative theme.

\section{Findings}

\subsection{Sample characteristics}

There were 13 females (68.4\%) and 6 males (31.6\%). Females, in general, tend to be slightly overrepresented among homeless youth (Rice et al., 2007; Whitbeck et al., 2004). Ten youth (52.6\%) self-identified as gay $(n=2)$, lesbian $(n=1)$, bisexual $(n=6)$, and transgendered $(n=1)(G L B T)$. Because interviewers were instructed to oversample sexual minorities because of their greater risk for HIV, their numbers in this subsample are higher than what we would typically see in the population of homeless youth. Ages ranged from 16 to 21 $(\mathrm{M}=19.47$ years). The majority was White $(\mathrm{n}=11 ; 57.9 \%)$ with the remaining youth self-identifying as Black $(n=4)$, Hispanic $(n=2)$, American Indian $(n=1)$, and biracial $(n=1)$. The average age at which youth first ran away from home was 13.2 years and they spend an average of two nights per week on the street. Additionally, the total number of times youth have run averages between four and ten times. Fourteen youth reported early sexual onset ( 9 to 14 years of age) and 12 individuals reported having eight or more lifetime sexual partners.

In terms of their social networks, homeless youth reported a mean of 5.53 network members whose overall average age was 26.0 years. The majority of youths' networks $(\mathrm{N}=16)$ were composed of both males and females and they reported interacting with their members between one to three times per week on average. Additionally, youth reported feeling "somewhat close to very close" to their network members and reported low conflict (i.e., "sometimes") with their network members.

Our findings include three main themes surrounding the sexual behaviors of homeless youth and their perceptions of their social networks. These include attitudes and norms that influence: 1) their decision to have sex, 2) their decision to use condoms, and 3) safe sex practices. Each of these themes is presented below.

\subsection{Decision to have sex}

Though homeless youth provide reasons for having sex that are similar to general adolescent populations, it is critical to focus on the context of these situations. Homeless youth generally do not have daily contact with parents and/or other family members and thus may not have the same access in obtaining advice or asking questions regarding safe sex practices like many housed adolescents (Secor-Turner et al., 2011; Stidham-Hall et al., 2012). Moreover, having the added benefit of parents to rely on for sexual health information has been shown to reduce the odds of having multiple sexual partners among housed adolescents (Secor-Turner et al., 2011). In contrast, homeless youth typically must rely on the knowledge and advice of their peer group, which in some cases, may be lacking or inaccurate, potentially posing significant health consequences for the youth. Additionally, because homeless youth may not accurately perceive the frequency with which their peers engage in risky sexual behaviors, these misconceptions can affect their own behavior. Thus, homeless youth have limited access to social and physical resources (e.g., family members, condoms, stable living situation) compared to their housed counterparts, and their decision to have sex may have dire consequences.

Homeless youth reported that personal and social group attitudes and norms that influenced their decision to have sex included chemistry and physical appearance as well as the length and stability of the dating relationship. Additionally, a potential partner's sexual history and substance use were also considered important factors when deciding whether or not to have sex.

\subsubsection{Chemistry and physical appearance}

Stephanie, a White, 20 year-old, bisexual reported that whether or not she engages in sex is related to her feelings, "Simply how I feel, and how I feel about that person. He [my fiancé]...respects me enough to know that if I don't want to do it [have sex] that night, he doesn't worry about it." Amanda, a White, bisexual, concurs and candidly adds, "There has to be some chemistry there or it's [sex] not going to happen." Along with chemistry, both Darnel, a Black, 21 yearold, heterosexual and Michael, a White, gay, 21 year-old, believe that physical appearance is also important.

Table 1. Individual and social network norm sample quotes.

\begin{tabular}{ll}
\hline Qualitative codes and subcodes & Selected qualitative quotes \\
\hline $\begin{array}{l}\text { Decision to have sex } \\
\text { Chemistry and physical appearance }\end{array}$ & $\begin{array}{l}\text {-There has to be some chemistry there or it's [sex] not going to happen. } \\
\text { Relationship length and stability }\end{array}$ \\
$\begin{array}{l}\text { Sexual history } \\
\text { Substance use }\end{array}$ & $\begin{array}{l}\text {-If I know that you mess around with nasty people that could possibly have something, like that, definitely a no. } \\
\text {-If my partner's been drinking or anything like that, I'd tell them before we start drinking, 'we ain't sleeping together } \\
\text { tonight or whatever.' }\end{array}$
\end{tabular}

Decision to use condoms Unknown sexual history Availability

Pregnancy and STI prevention
-I use a condom with everyone I have sex with and I don't know if he's hav[ing] sex with other people or not. -We don't use protection... and it's really hard to find [them]. We've looked everywhere. And we just can't find it [condoms]... even when we knew we were both clean we wanted to use protection but... [never did]. -Not trying to get pregnant anymore, and not trying to catch anything.

Safe sex practices

Do not discuss safe sex Discuss safe sex
-Yah-yah if you use a condom, you use a condom. You know that's just how it is... but we don't talk [about it]. -They [network members] pound it in[to] my head a lot, especially D.J. 'Always use protection.' 


\subsubsection{Relationship length and stability}

Being in a steady relationship was a prerequisite for having sex for nine females. Elizabeth explains, "I don't have sex with somebody I don't know or I have to get to know [them], and I've got to know [them] for at least six months [before having sex]" (White, heterosexual). In contrast, Jennifer mentioned that she had to know her sexual partner for more than $24 \mathrm{~h}$ (19 year-old, White, bisexual). Despite these general timeframes, it is possible that some of these youth may not have enough time to get to know their partners and establish safe sex boundaries or practices. Though we had fewer males in the sample, none of the young men discussed relationship length or stability as a criterion for having sex. In other words, the attitudes and norms within their peer group were such that relationship length and stability did not impact their decision.

\subsubsection{Sexual history}

Knowing about a person's sexual history was a factor several youth discussed within their peer group that influenced their decision of whether or not to have sex. Individuals who previously had STIs or multiple sexual partners are viewed as having an undesirable sexual past according to these respondents. As such, eight homeless youth took steps toward learning about their partner's sexual background. Brittany explained that both she and her potential sexual partner would have to "get checked out" (i.e., be tested) to ensure neither currently had an STI prior to engaging in sexual activities (18 year-old, bi-racial, bisexual). Because this may require prior planning on the part of youth, it is possible that some young people may be unwilling to wait and thus have sex without confirming that a person is infection free. For those youth who are unable to obtain this information directly, they may use visual cues such as appearance or base their evaluation on an individual's reputation or behavior (e.g., signs of promiscuity) when trying to determine sexual history (Brown et al., 2012). Additionally, previous research suggests that homeless youth are less likely to worry about the consequences of engaging in highrisk sexual behaviors with their social network members because they feel they "know" them and are thus less likely to use protection (Tyler \& Melander, 2010). Other youth may be embarrassed about having had an STI and thus may not be forthcoming about their sexual history with a potential partner. According to David, a White, gay 21 year-old, "... most people now days they, you know, they mind their own business. If someone's got something [STI], and people who have something, ain't gonna admit [it] to no-one anyway." Other than through an in-depth medical exam, it may be difficult to know whether or not one's partner is free of STIs as some youth may lie about their health status as David describes.

\subsubsection{Substance use}

Rodrigo, David, and Michael discussed network norms surrounding substance use and stated that they would not engage in sexual activities with someone who was under the influence of alcohol or drugs. For example, Rodrigo, a Hispanic bisexual 20 year-old stated, “...if my partner's been drinking or anything like that, I'd tell them before we start drinking, 'we ain't sleeping together tonight or whatever." Another youth, David, reportedly asks himself, "Am I in the mood?... Um, how much liquor have I had?... What do I have to do tomorrow in the morning?" Although David was perhaps being facetious, it is possible that in addition to consuming alcohol, other factors may impact youths' decisions to have sex. Michael admits that he is less inhibited in his actions while intoxicated ("Like, that's why, I mean - I'm a whore when I'm drunk" [laughs]), suggesting a positive association between alcohol consumption and the decision to have sex.

\subsection{Decision to use condoms}

Youth were also queried about their group norms regarding the use of condoms. Both males and females discussed condom usage as it related to a variety of factors including unknown sexual history, availability, and pregnancy and STI prevention. Though three youth strongly endorsed condom use whereas two youth were adamantly against it, the majority fell somewhere in between the extremes.

\subsubsection{Unknown sexual history}

Michael says that although he always wears condoms, he is unsure of his partners' condom use history: “....actually partner two, J.P. ... he don't like to use a condom, but, for me it's kind of weird you know 'cause I use a condom with everyone I have sex with and I don't know if he's hav[ing] sex with other people or not." David, who is also gay, implies that he will use a condom if he thinks a potential partner has a history of STIs but his later remarks indicate inconsistencies in his usage as well as that of his network members. Even though Michael and David know the risks of having unprotected sex, this knowledge does not translate into behavior for them or their social network members.

\subsubsection{Availability}

Although study youth generally recommend condom use, they only use them when they are available and not having a condom does not preclude them from having sex. For example, Lulu is ambivalent about condom use; she and her steady partner will use a condom if one is available but remarked that they are still going to have sex with or without a condom. It is possible that Lulu and others are less likely to use condoms because they are currently in monogamous relationships whereas Michael is more likely to use condoms because he is sexually active with multiple partners. These findings are supportive of the literature in which researchers have found that for both males and females, the most predictable factor associated with not wearing a condom is having sex with only one partner (MacKellar et al., 2000).

\subsubsection{Pregnancy and STI prevention}

Brittany reported using condoms to prevent pregnancy and STIs. Females' responses reveal that preventing pregnancy was paramount as indicated by their willingness to use birth control but not insisting on condom use. This may be explained by the fact that women have less control in sexual situations and may not always be able to effectively negotiate condom use. Megan says that she has never used condoms. In her words, "If they wanted to use and they had it on them we could use it but I never provided it [condom], [and] I never asked for it. I was on birth control but that was it."

Although five youth were either completely supportive or adamantly against using condoms, youth were generally inconsistent in their use of condoms during sex. Megan, one of the youth who is against using condoms, reports that they were unnecessary in a previous heterosexual relationship because she had difficulties getting pregnant. In other words, Megan believes that condoms are useful for preventing pregnancy but appears to dismiss their usefulness for protecting against STIs.

\subsection{Safe sex practices}

Our final theme, safe sex practices, is divided into two sub themes. Current study youth either discuss safe sex practices with their partners and network members or they do not discuss these topics. We begin by introducing youth who do not discuss safe sex.

\subsubsection{Do not discuss safe sex}

Sixteen youth explained that there are no norms within their network regarding safe sex practices. When the interviewer probes and asks Jamal (Black, 19 year-old, heterosexual) if his network members ever discuss safe sex or using condoms, Jamal says, "No, because neither one of them [network members] liked using condoms." His response suggests that because they do not like to wear condoms during sexual 
activity, no group norms exist on this issue. Perhaps using condoms is an "unwritten rule" and thus is normative among their group. David, for example, says that he does not discuss condoms with his network members but implies that they "just wear condoms" and do not generally discuss it. As such, David assumes his network members are engaging in safe sex practices but not openly discussing it amongst themselves which supports social norms theory.

\subsubsection{Discuss safe sex practices}

Only three youth we spoke with said they have norms within their network regarding safe sex practices. According to Michael, "Yes, we actually talk a lot about safe sex practice, 'cause, um, she [network member] knows how I am- I have friends with benefits- and she's like 'Well, you better be using a condom!'” Amanda also reports, "They [network members] pound it in [to] my head a lot, especially D.J. [who says] 'Always use protection"' and her other network members also strongly encourage her to carry a condom at all times. These two quotes suggest that these youth belong to social networks that have specific rules actively encouraging safe sex practices; however, it appears that they perceive condom use as the only safe sex method and may not consider other ways to protect themselves.

\section{Discussion}

In order to mitigate the high-risk sexual behaviors of homeless youth, it is crucial to understand the broader context of their lives, including social network norms and activities as they relate to homeless youth's own sexual behaviors. Although previous studies find high rates of risky sexual behavior among homeless youth (Bailey et al., 1998; Halcon and Lifson, 2004; Rew et al., 2008; Tevendale et al., 2009; Tyler and Johnson, 2006), which places them at greater risk for STIs or HIV (Kipke et al., 1998; Rice et al., 2007; Tyler, 2008), we know little about the decisions and rationale behind their unsafe behavior. The current narratives of these young people provide important contextual information regarding their social environments and reveal several norms within their social networks which help explain their sexual behavior. Our findings are also generally supportive of social norms theory (Martens et al., 2006) such that homeless youth have perceptions about their network members' sexual behaviors (e.g., condom use) that may potentially influence their own actions, even if their perceptions are not totally accurate.

It is noteworthy that nine youth discuss preventative measures within their network when deciding whether or not to have sex such as avoiding substance using individuals or those with an undesirable sexual history given the potential negative health consequences of such interactions. This precaution on the part of the youth is a significant finding given the risky sexual behavior (Halcon and Lifson, 2004; Johnson et al., 1996; MacKellar et al., 2000; Rew et al., 2008; Tyler et al., 2001) and high rates of substance use (Bailey et al., 1998) found among many homeless youth. Overall our findings from this theme suggest that at least nine of the current study youth contemplate the outcomes of high-risk behavior within their networks and are making informed decisions when they abstain from sex in certain circumstances.

According to our study youth, the decision to use condoms is influenced by unknown sexual history, availability, and health concerns such as pregnancy and STIs. Two youth explicitly discussed the fact that some sex partners are less than forthcoming about their sexual history, and as a result, are more likely to wear condoms when having sex with these individuals. Four young women specifically report using condoms early on in the relationship but that usage tapered off over time. Youth also spoke of the difficulties in locating condoms in general or their lack of availability when they wanted to have sex. Young people who report monogamous relationships appear to be less concerned about promiscuous partners. Although 16 youth and their social networks recognize the connection between condom us- age and preventing pregnancy and STIs, 3 young women only spoke about condoms as they relate to pregnancy prevention. In other words, if they were not concerned about becoming pregnant, they did not feel a need to use condoms. This rationale overlooks the utility of condoms and other safe sex measures in preventing STIs and assumes that their partner will remain faithful. Inconsistent condom usage was the norm among these homeless youth and their networks. Overall, it appears that most young people in our sample recognize the link between wearing condoms and preventing pregnancy and infection as most report condom usage in the initial stages of the relationship. Over time, however, this practice wanes as youth ease into their relationship, sexual activity becomes routine, and youth become more trusting of their partner.

The final theme, safe sex practices, is particularly telling because even though all of these homeless youth appear somewhat knowledgeable about condom usage and its relation to STIs and/or pregnancy, the fact remains that 16 out of 19 youth report that their social networks do not have norms regarding safe sex practices. The actual behavior of the 16 individuals also reveals inconsistent condom usage compared to the three individuals whose social networks strongly endorse safe sex practices and where youth's behavior mirrors those practices. Thus, if homeless youth believe that their social network members seldom use condoms when having sex, then homeless youth themselves may be more likely to engage in unsafe sexual practices placing them at risk for HIV infection.

\subsection{Limitations}

Some limitations should be noted. Because we gathered information on a small, convenience sample of homeless youth, our findings may not be representative of all homeless youth in our age range. Additionally, the qualitative sample included an overrepresentation of racial/ethnic minorities, females, and GLBT youth, which may have influenced our findings. Even though we suggest that youth are influenced by their social networks, it is equally plausible that the youth are drawn to these groups due to homophily and bond with these individuals because they engage in similar high risk behaviors. Finally, we did not ask the social network members about their actual behavior but rather relied on youth reports of their perceptions of their social network members' norms and attitudes. Extensive research, however, has shown that perceptions are just as important as actual behavior (Wigfield, Eccles, Schiefele, Roeser, \& Davis-Kean, 2006). That is, if youth believe their network members have a particular viewpoint this is likely to influence their behavior regardless of the network members' actual thoughts.

\subsection{Conclusion}

Even if study youth are aware of the sexual risks, if they think they "know" their sexual partner (Tyler \& Melander, 2010), and they perceive their relationship as monogamous, they are less likely to practice safe sex. Though at least 17 youth have good intentions when it comes to using condoms, this practice generally wanes over time as youth become more trusting and perhaps less concerned about the consequences (e.g., I haven't gotten pregnant yet). Additionally, according to 16 youth, their social networks do not have norms regarding safe sex practices. In summary, our study advances the literature on sexual activity among homeless youth and their social networks by providing insight into the reasons behind their decision making process and specific group norms surrounding these practices.

\subsection{Policy implications}

At the policy level, these findings suggest that intervention needs to focus on changing social norms among homeless youth. Previous research has focused on challenging social norms regarding HIV risk 
behavior through discussion, debate, and role play activities and has found evidence of community change across different cultures (Maticka-Tyndale \& Barnett, 2010). Mass media has also promoted behavior change such as increasing acceptance of condoms by enhancing protective behaviors among youth at high risk for HIV (Romer et al., 2009). Additionally, this campaign successfully changed youths' beliefs regarding unnecessary condom use with safe partners. Similarly, agencies and organizations that serve homeless youth could use Facebook postings to promote safe sex behaviors such as condom use, which may potentially lead to changing social norms within their social networks. Positive outcomes of using condoms (i.e., reduced stress surrounding acquiring STIs and becoming pregnant) could also be posted to Facebook pages of agencies who serve homeless youth; this strategy of focusing on beneficial outcomes of condom use has been shown to be effective in research with high risk youth populations (cf. Horner et al., 2008, cited in Romer et al., 2009). Finally, peer-led initiatives through street outreach may be an effective way to alter social norms as pro-social peers have been found to reduce HIV risk behaviors (Rice et al., 2007). Changing homeless youths' social network norms regarding safe sex through community, media, and street outreach initiatives may help them improve their lives.

Acknowledgments - This research was supported by a grant from the National Institute on Drug Abuse (DA021079), Dr. Kimberly A. Tyler, PI.

\section{References}

American Public Human Services Association (1999). Adolescents served by child welfare agencies: The risk of HIV, STDs, and unintended pregnancies. Washington, DC:Author.

Bailey, S. L., Camlin, C. S., \& Ennett, S. T. (1998). Substance use and risky sexual behavior among homeless and runaway youth. Journal of Adolescent Health, 23, 378-388.

Brown, R. A., Kennedy, D. P., Tucker, J. S., Wenzel, S. L., Golinelli, D., Wertheimer, S. R., et al. (2012). Sex and relationships on the street: How homeless men judge partner risk on skid row. AIDS and Behavior, 16, 774-784.

Cairns, R. B., Leung, M., \& Cairns, B. D. (1995). Social networks over time and space in adolescence. In L. J. Crockett,\&A. C. Crouter (Eds.), Pathways through adolescence: Individual development in relation to social contexts (pp. 35-56). New Jersey: Lawrence Erlbaum Associates.

Centers for Disease Control and Prevention (2002a). Initiation of services in the Boston HAPPENS program: HIV-Positive, homeless, and at-risk youth can access services. The body: An AIDS and HIV information resource Retrieved December 5, 2006, from http://www.thebody.com/ cdc/news updates archive/dec5 02/youth hiv.html

Centers for Disease Control and Prevention (2002b). Young people at risk: HIV/AIDS among America's youth. Retrieved February 17, 2005, from http://www.cdc.gov/hiv/pubs/facts/youth.pdf

Centers for Disease Control and Prevention (2008). HIV/AIDS among youth. Retrieved February 20, 2011, from http://www.cdc.gov/hiv/resources/factsheets/PDF/youth.pdf

Creswell, J. W., \& Plano Clark, V. L. (2011). Designing and conducting mixed methods research (2nd ed.). Thousand Oaks, CA: Sage.

Ennett, S. T., Bailey, S. L., \& Federman, E. B. (1999). Social network characteristics associated with risky behaviors among runaway and homeless youth. Journal of Health and Social Behavior, 40, 63-78.

Farrow, J. A., Deisher, R. W., Brown, R., Kulig, J. W., \& Kipke, M. D. (1992). Health and health needs of homeless and runaway youth: A position paper of the society for adolescent medicine. Journal of Adolescent Health, 13, 717-726.

Fisher, J. D. (1988). Possible effects of reference group-based social influence on AIDS-risk behavior and AIDS prevention. American Psychologist, 43, 914-920.
Hagan, J., \&McCarthy, B. (1997). Mean streets: Youth crime and homelessness. New York: Cambridge University Press.

Halcon, L. L., \& Lifson, A. R. (2004). Prevalence and predictors of sexual risks among homeless youth. Journal of Youth and Adolescence, 33, 71-80.

Horner, J. R., Romer, D., Vanable, P. A., Salazar, L. F., Carey, M. P., Juzang, I., et al. (2008). Using culture-centered qualitative formative research to design broadcast messages for HIV-prevention for African American adolescents. Journal of Health Communication, 13, 309-325.

Johnson, T. P., Aschkenasy, J. R., Herbers, M. R., \& Gillenwater, S. A. (1996). Self-reported risk factors for AIDS among homeless youth. AIDS Education and Prevention, 8, 308-322.

Kipke, M. D., Unger, J. B., Palmer, R. F., Iverson, E., \& O’Connor, S. (1998). Association between self-identified peer-group affiliation and HIV risk behaviors among street youth. In J. B. Greenberg, \& M. S. Neumann (Eds.), What we have learned from the AIDS evaluation of street outreach projects (pp. 61-82). Atlanta, GA: Centers for Disease Control.

MacKellar, D. A., Valleroy, L. A., Hoffmann, J. P., Glebatis, D., LaLota, M., McFarland, W., et al. (2000). Gender differences in sexual behaviors and factors associated with nonuse of condoms among homeless and runaway youths. AIDS Education and Prevention, 12, 477-491.

Martens, M. P., Page, J. C., Mowry, E. S., Damann, K. M., Taylor, K. K., \& Cimini, M. D. (2006). Differences between actual and perceived student norms: An examination of alcohol use, drug use, and sexual behavior. Journal of American College Health, 54, 295-300.

Maticka-Tyndale, E., \& Barnett, J. P. (2010). Peer-led interventions to reduce HIV risk of youth: A review. Evaluation and Program Planning, $33,98-112$.

Miles, M. B., \& Huberman, A. M. (1994). Qualitative data analysis: An expanded sourcebook (2nd ed.). Thousand Oaks, CA: Sage.

Montgomery, S. B., Hyde, J., De Rosa, C. J., Rohrbach, L. A., Ennett, S., Harvey, M., et al. (2002). Gender differences in HIV risk behaviors among young injectors and their social network members. The American Journal of Drug and Alcohol Abuse, 28, 453-475.

Muhr, T. (2004). User's manual for ATLAS.ti 5.0 (2nd ed.). Berlin, Germany: Scientific Software Development.

Perkins, H. W. (2002). Social norms and the prevention of alcohol misuse in collegiate contexts. Journal of Studies on Alcohol, 14, 164-172 (Supplement).

Rew, L., Grady, M., Whittaker, T. A., \& Bowman, K. (2008). Interaction of duration of homelessness and gender on adolescent sexual health indicators. Journal of Nursing Scholarship, 40, 109-115.

Rice, E., Milburn, N. G., \& Rotheram-Borus, M. J. (2007). Pro-social and problematic social network influences on HIV/AIDS risk behaviours among newly homeless youth in Los Angeles. AIDS Care, 19, 697-704.

Rice, E., Stein, J. A., \& Milburn, N. (2008). Countervailing social network influences on problem behaviors among homeless youth. Journal of Adolescence, 31, 625-639.

Romer, D., Sznitman, S., DiClemente, R., Salazar, L. F., Vanable, P. A., Carey, M. P., et al. (2009). Mass media as an HIV-prevention strategy: Using culturally sensitive messages to reduce HIV-associated sexual behavior of at-risk African American youth. American Journal of Public Health, 99, 2150-2159.

Rotheram-Borus, M. J., Mahler, K. A., Koopman, C., \& Langabeer, K. (1996). Sexual abuse history and associated multiple risk behavior in adolescent runaways. The American Journal of Orthopsychiatry, 66, 390-400.

Secor-Turner, M., Sieving, R. E., Eisenberg, M. E., \& Skay, C. (2011). Associations between sexually experienced adolescents' sources of information about sex and sexual risk outcomes. Sex Education, 11, 489-500.

Stidham-Hall, K., Moreau, C., \& Trussell, J. (2012). Patterns and correlates of parental and formal sexual and reproductive health communication for adolescent women in the United States, 2002-2008. Journal of Adolescent Health, 50, 401-413. 
Tevendale, H. D., Lightfoot, M., \& Slocum, S. L. (2009). Individual and environmental protective factors for risky sexual behavior among homeless youth: An exploration of gender differences. AIDS and Behavior, 13, 154-164.

Tyler, K. A. (2008). Social network characteristics and risky sexual and drug related behaviors among homeless young adults. Social Science Research, 37, 673-685.

Tyler, K. A., Hoyt, D. R., \& Whitbeck, L. B. (2000). The effects of early sexual abuse on later sexual victimization among female homeless and runaway youth. Journal of Interpersonal Violence, 15, 235-250.

Tyler, K. A., Hoyt, D. R., Whitbeck, L. B., \& Cauce, A. M. (2001). The impact of childhood sexual abuse on later sexual victimization among runaway youth. Journal of Research on Adolescence, 11, 151-176.

Tyler, K. A., \& Johnson, K. A. (2004). Victims and offenders: Accounts of paybacks, invulnerability, and financial gain among homeless youth. Deviant Behavior, 25, 427-449.

Tyler, K. A., \& Johnson, K. A. (2006). Trading sex: Voluntary or coerced? The experiences of homeless youth. Journal of Sex Research, 43, 208-216.

Tyler, K. A., \& Melander, L. A. (2010). The effect of drug and sexual risk behaviors with social network and non-network members on homeless youth's STI and HIV testing. Sexual Health, 7, 434-440.
Tyler, K. A., Whitbeck, L. B., Chen, X., \& Johnson, K. (2007). Sexua health of homeless youth: Prevalence and correlates of sexually transmissible infections. Sexual Health, 4, 57-61.

Van Leeuwen, J. M., Hopfer, C., Hooks, S., White, R., Petersen, J., \& Pirkopf, J. (2004). A snapshot of substance abuse among homeless and runaway youth in Denver, Colorado. Journal of Community Health, 29, 217-229.

Whitbeck, L. B., Chen, X., Hoyt, D. R., Tyler, K. A., \& Johnson, K. D. (2004). Mental disorder, subsistence strategies, and victimization among gay, lesbian, and bisexual homeless and runaway adolescents. Journal of Sex Research, 41, 329-342.

Whitbeck, L. B., \& Hoyt, D. R. (1999). Nowhere to grow: Homeless and runaway adolescents and their families. New York, NY: Aldine de Gruyter.

Wigfield, A., Eccles, J. S., Schiefele, U., Roeser, R. W., \& Davis-Kean, P. (2006). Development of achievement motivation. In N. Eisenberg, W. Damon, \& R. M. Lerner (Eds.), Handbook of child psychology, volume 3: Social, emotional, and personality development (pp. 933-1002). (6th ed.). Hoboken, NJ: John Wiley \& Sons, Inc. 